\title{
Realizing Societal Benefit from Academic Research: Analysis of the National Science Foundation's Broader Impacts Criterion
}

\author{
Melanie R. Roberts
}

The National Science Foundation (NSF) evaluates grant proposals based on two criteria: intellectual merit and broader impacts. NSF gives applicants wide latitude to choose among a number of broader impacts, which include both benefits for the scientific community and benefits for society. This paper considers whether including potential societal benefits in the Broader Impacts Criterion leads to enhanced benefits for society. One prerequisite for realizing societal benefit is to transfer research results to potential users in a meaningful format. To determine whether researchers who discuss broader impacts for society are more likely to engage in broad dissemination activities beyond the scientific publication, I analysed proposed broader impacts statements from recent award abstracts. Although 43\% of researchers discussed potential benefits for society, those researchers were no more likely to propose dissemination of results to potential users than researchers who only discussed broader impacts for science. These findings suggest that considering potential societal benefit as a broader impact may not lead to more actual societal benefits and that many potentially useful results may not be disseminated beyond the scientific community. I conclude with policy recommendations that could increase the likelihood of realizing potential societal benefits from academic research.

Keywords: Broader Impacts; Societal Benefit of Science; Public Dissemination; Scientific Partnerships; Use-inspired Research; Linear Model of Science

Melanie R. Roberts is a Visiting Fellow in the Center for Science and Technology Policy Research at the University of Colorado. Correspondence to: Melanie R. Roberts, Center for Science and Technology Policy Research, Cooperative Institute for Research in Environmental Sciences, University of Colorado, 1333 Grandview Avenue UCB-488, Boulder, CO 80301, USA. Email: melanie.r.roberts@colorado.edu 


\section{Introduction}

In 1997 the National Science Foundation (NSF) announced the review criteria that are still used to evaluate grant proposals as of 2009: what is the intellectual merit of the proposed activity, and what are the broader impacts of the proposed activity? To address the Broader Impacts Criterion (BIC), researchers may choose among a number of options, which include both broader impacts for the scientific community (e.g. shared instrumentation or training students), and broader impacts for society (e.g. potential utility for policy-makers or industry and public outreach).

This report contributes the first descriptive data that illustrate how researchers actually address BIC to an ongoing scholarly debate over the utility of the broader impacts review criterion (Bozeman and Sarewitz 2005; Holbrook 2005). I will first review the role of NSF and the broader impacts review criterion in the larger context of the publicly funded research in the United States, which generally separates basic and applied research in different agencies or departments. Second, I will draw on previous research to argue that realizing societal benefits from research requires communication of research results to potential users in society in formats beyond the scholarly journal article. Then I will present an analysis that describes how researchers address BIC. Based on this analysis, science policy literature, and my experience as an AAAS science and technology policy fellow at NSF, I will then conclude by offering policy recommendations for how NSF might enhance the likelihood that research results will be utilized by society.

This analysis of broader impacts statements from recent award abstracts reveals that $89 \%$ of researchers propose broader impacts for science, $43 \%$ discussed potential benefits for society and $37 \%$ proposed dissemination activities beyond the scholarly community. However, those who discussed potential societal benefits were no more likely to propose dissemination activities than researchers who only discussed broader impacts for science. This result suggests that including benefits for society in BIC may be of limited use for increasing societal benefits from research. Policies that improve dissemination activities, including collaboration with potential users, could help to enhance the potential that research results will be utilized for societal benefit.

\section{Background: History of the National Science Foundation}

World War II marked a turning point in government support for scientific research (Kleinman 1995; Smith 1990). Impressed with the contribution of science and technology to the war effort, President Roosevelt asked Vannevar Bush, the Director of the Office of Scientific Research and Development, to develop a strategy that would capture benefits from scientific research during peace time. In his report, Science: The Endless Frontier, Bush suggested creating a new government agency-the National Research Foundation - to fund basic scientific research and education in universities and research institutes (Bush 1945). Bush, a prominent engineer, echoed the scientific community's concern about government interference in university research activities. 
He argued that basic research is a long-term process and should be insulated from short-term political goals by placing it in an agency that has no mission other than basic research, and made a careful distinction between basic and applied science:

Basic research is performed without thought of practical ends. It results in general knowledge and an understanding of nature and its laws. This general knowledge provides the means of answering a large number of important practical problems, though it may not give a complete specific answer to any one of them. The function of applied research is to provide such complete answers. (Bush 1945)

Thus, basic science became the domain of experts, who were uniquely qualified to judge the best research agenda for understanding the laws of nature.

As Congress debated the creation of Bush's proposed research funding agency, other agencies were developing their own strategies to address post-war research funding. The Atomic Energy Commission, which had overseen the Manhattan Project, began to support basic research in physics; the Public Health Service's National Institute of Health began an extramural grant programme; and Congress authorized the Office of Naval Research in 1946, which funded university-based basic and applied research of interest to the Navy. Thus, by the time President Truman signed the bill to create NSF in 1950, Bush's vision of a unified science funding agency was not politically feasible (Kelves 1977). Instead, the defining characteristic of NSF was its mission to perform basic research that advances scientific understanding, while the "mission agencies" funded scientific research that was related to a particular societal application.

\section{The Problem with the Linear Model of Science}

The political justification for government support of basic research has changed very little from Vannevar Bush's justification in 1945:

Advances in science will also bring higher standards of living, will lead to the prevention or cure of diseases, will promote conservation of our limited national resources, and will assure means of defense against aggression. (Bush 1945)

In a memo to research agency heads to highlight administration priorities for research in federal year 2005, President George W. Bush's advisors highlighted applications relevant to their priorities:

Science and technology contribute significantly to the highest priorities of this Administration: winning the war on terrorism, securing the homeland, and strengthening the economy. (Marburger III and Daniels 2003)

The Obama administration very closely echoed Vannevar Bush's original justification for research in its 4 August 2009 memo that outlining federal year 2011 research priorities for research agency heads:

Scientific discovery and technological innovation are major engines of increasing productivity and are indispensible for promoting economic growth, safeguarding the environment, improving the health of our nation and safeguarding our national security. (Orzag and Holdren 2009) 
These social justifications for scientific research reflect the prevailing model of science and innovation, often called the linear model, which assumes that increases in fundamental knowledge will lead to societal benefit through an orderly process of applied research, followed by development of new products or processes. However, this model has been challenged by both Congress and by science and innovation policy scholars. In 1968, Congress passed an amendment that authorized NSF to fund applied research (and social science research). Then, under pressure from the Nixon White House, NSF established Research Applied to National Needs (RANN), which was probably the most controversial programme in its history. Between 1970 and 1977, RANN awarded over half a billion dollars to research projects that promised to improve the environment, energy production, urban planning, and more. However, RANN never gained favour among either NSF staff or university researchers, who saw RANN as a threat to basic research funding (Green and Lepkowksi 2006; Mazuzan 1994).

Despite the recent political success of the linear model to justify greater government investment in basic research to keep the United States economically competitive (National Academy of Sciences 2006), challenges to the linear model continue. For example, an 4 August 2009 Obama administration memo to scientific funding agencies outlining spending priorities for the 2011 budget may tacitly challenge the linear model (Goldston 2009). Not only did the memo neglect to mention basic research, but it also called for less separation between knowledge producers and users by encouraging collaborations between "people involved in making and using things" and encouraging agencies to explore open innovation to "become highly open to ideas from many players at all stages" (Orzag and Holdren 2009).

Challenges to the linear model are not merely political. Science and innovation policy scholars have long discredited the model (Branscomb, Holton, and Sonnert 2002; Pielke and Byerly 1998 ; Etzkowitz and Leysdorff 2000; Funtowicz 1993; Gibbons et al. 1994 ; Guston and Keniston 1994; Kitcher 2001; Sarewitz and Pielke 2007; Sarewitz 1996; Stokes 1997). One of the leading alternatives to the linear model is Donald Stokes' Quadratic Model of science. Stokes suggested that, instead of classifying research on a one-dimensional scale that puts basic research and considerations of use in opposition, it would be more useful to categorize research in two dimensions, with axes for both fundamental understanding and considerations of use (Stokes 1997). Holbrook (2005) also suggests that Stokes' "use-inspired basic research" might be more consistent with BIC than the Bush conception of basic research. Indeed, a number of research communities now promote "use-inspired research", including the sustainability science community (Brint 2005; Clark 2007). In addition, "use-inspired research" is being promoted at an institutional level at several universities, most prominently at Arizona State University. ${ }^{1}$

\section{A Compromise: Considering Potential Societal Applications in Merit Review}

To reconcile the tension between the linear model and the practically-oriented justification for funding basic research, NSF has considered potential societal use during merit review of grant proposals since the 1960s. However, the National Science 
Board's ${ }^{2}$ first directive regarding the consideration of "potential applications" clearly indicated that it was to be used only as a tiebreaker among proposals with equally good scientific merit:

This criterion [of potential applications] is, of course, more relevant in the case of engineering research than in other programs of the NSF. But the question deserves a consideration and might, on rare occasions, serve as a criterion for preferring a project which is not markedly superior in scientific merit to others near the cutoff line for support.

(National Science Board 1967, 218)

The merit review criteria were revised again in 1974 and $1981,{ }^{3}$ but still included consideration of social utility. In 1997 the National Science Board announced the two merit review criteria that are still used as of 2009: what is the intellectual merit of the proposed activity, and what are the broader impacts of the proposed activity?

BIC is just that: extremely broad. A laundry list of factors may be considered during evaluation of BIC. The following is the summary of possible factors that may be considered in evaluating broader impacts, as stated in the NSF Grant Proposal Guide:

- How well does the activity advance discovery and understanding while promoting teaching, training and learning?

- How well does the proposed activity broaden the participation of underrepresented groups (e.g. gender, ethnicity, disability, geographic, etc.)?

- To what extent will it enhance the infrastructure for research and education, such as facilities, instrumentation, networks and partnerships?

- Will the results be disseminated broadly to enhance scientific and technological understanding?

- What may be the benefits of the proposed activity to society?

Although individual NSF funding programmes may provide additional instructions, NSF does not give general guidance on which broader impacts are preferred, how many to address, or how broader impacts will be weighed against the intellectual merit criterion. Thus, discussion of potential benefit for society is just one choice among many potential broader impacts. Researchers are free to choose not to speculate about societal benefits, and may instead propose broader impacts for the scientific community, such as training students, broadening participation in science, or contributing to infrastructure for research or education.

The above examples of broader impacts were mostly modified from the previous four merit review criteria. The only broader impact adopted in 1997 that had not been previously included in merit review criteria was broad dissemination of research results. Prior NSF policy had encouraged publication of research in scholarly journals. However, the "broad dissemination" broader impact includes dissemination efforts beyond scholarly publication, which could benefit either science or society. In a July 2007 memorandum, ${ }^{4}$ NSF enumerated a number of ways to address broad dissemination. They include activities that benefit science, including participating in interdisciplinary conferences and making data available in multiple formats. In addition, outreach activities such as giving public presentations or partnering with museums could increase support for science generally. Dissemination efforts that could benefit 
society include involving the public or industry in research and education activities, and presenting research and education results in formats useful to policy-makers, members of Congress, industry, and broad audiences.

\section{Broad Dissemination Facilitates Utilization of Research Results}

The linear model holds that basic research fills a figurative "reservoir of knowledge" from which societal users-namely industry and the government-can draw. However, the linear model does not describe how to reconcile the supply of knowledge that goes into the reservoir with the demand by users (Sarewitz and Pielke 2007), nor does it suggest how potentially useful information is transferred from the vast reservoir to those who can use it. The linear model is "trickle-down" or "science-push", and assumes that basic science will automatically find its way to users or practitioners (for review, see Marinova and Phillimore 2003). However, researchers in social and policy sciences have demonstrated that including potential users in knowledge production and dissemination of research in useful formats for users increases the likelihood that knowledge will ultimately be utilized (Dilling 2007; Gibbons et al. 1994; Huberman 1990; McNie 2007).

Even Vannevar Bush recognized the importance of dissemination of research results. In Science: The Endless Frontier, Bush suggested that "the Government should accept new responsibilities for promoting the flow of new scientific knowledge" (1945). For example, he suggested partnerships between basic researchers and the military as a means of transferring useful knowledge. However, NSF's role in promoting the flow of scientific knowledge outside the scientific community has generally been to encourage publication of NSF-funded studies in scholarly journals and to issue press releases about particularly exciting research results.

Thus, the "broad dissemination" broader impact could help to improve the dissemination of research results to potential users, which would consequently enhance the likelihood that they will be utilized by society. This paper will describe how often potentially useful results are disseminated outside the scientific community. If the researchers who discuss potential societal benefits are really "use-inspired", my hypothesis is that they will also be more likely to engage in dissemination activities that transfer useful results to potential users. An alternative hypothesis is that researchers simply speculate on potential benefits to "use-justify" research that is actually curiosity driven. Indeed, "use justification" is the easiest way to fulfil BIC, because it is the only broader impact that does not require any action on the researcher's part.

\section{Methods}

Sample

Neither unsuccessful grant proposals nor full project descriptions for funded proposals are publicly available. Similarly, although NSF collects some information about broader impacts from awardees in annual reports, these are not publicly available, so it is not 
possible to determine whether researchers follow through with proposed broader impacts or whether they performed different broader-impacts activities than were originally proposed.

Thus, only broader impacts as described in the award project summaries are included in this analysis. I analysed 294 project summaries from NSF research awards made between 1 October 2006 and 30 September 2008. To control for project duration, I selected only new grants of three years in duration. To enrich the sample for researchers who paid attention to broader impacts, and were thus more likely to be aware of the choices of broader impacts activities, I used NSF's online award search tool to select project summaries that contained the words "broad* impact*". Of the project summaries matching these criteria, I randomly selected 42 project proposals from each of the following six directorates: Biological Sciences (BIO); Social Behavioral and Economic Sciences (SBE); Computer Science and Engineering (CSE); Math and Physical Sciences (MPS); Geosciences (GEO); and Engineering (ENG). I also included 42 proposals from the Office of Polar Programs (OPP). The Directorate of Education and Human Resources was not included in this analysis.

\section{Coding Broader Impacts}

For each project summary, I coded the proposed broader impacts based on NSF's July 2007 broader impacts guidance document. ${ }^{5}$ The coding criteria for broader impacts for science and broader impacts for society are presented in Table 1. Many projects had multiple broader impacts, and a small number of proposers misunderstood the criterion. Those who misunderstood generally discussed the potential impacts on the advancement of scientific understanding, which should be reviewed as a part of the intellectual merit criterion. To test the statistical significance of differences in the frequency of proposed broader impacts, I used an online calculator to estimate the $Z$-score for two proportions. ${ }^{6}$

I further examined all proposals that both discussed potential societal benefits and proposed dissemination activities to determine whether the potential societal benefits were likely to be recognised in the short term or long term. I judged the impacts to be short term if the researcher identified both potential users and a societal problem that could be mostly answered by the one study.

\section{Results}

Do Researchers Choose Broader Impacts for Science or for Society?

In 2001 the National Academy of Public Administration studied the reviews from 25 proposals, and found that only about one-quarter of reviewers discussed BIC (National Academy of Public Administration 2001). NSF responded by returning proposals without review if they did not mention the broader impacts beginning on 1 October 2002. The policy was apparently successful for increasing attention to broader impacts, because NSF only returned 325 (1.14\%) proposals without review 
Table 1 Criteria for Coding Broader Impacts

Criteria for science

Infrastructure for Science

Broaden Participation

Training and Education

Academic Collaborations

K-12 Outreach

Criteria for society

Potential Societal Benefits

Outreach/Broad

Dissemination

Partnerships with

Potential Users of

Research Results
Creation of a new research methodology, tool, or data source that will be useful to advance science

Recruiting or including under-represented groups in research or in outreach efforts. Includes efforts to attract women to science and to keep them in the academic pipeline for all fields, but excludes funding female students in biology and social sciences

Includes mentoring undergraduates, graduate students, and postdoctoral fellows in the laboratory and teaching classes

Research collaborations with other universities in the United States or abroad

Outreach to K-12 students or teachers helps to get kids excited about science and ensure a pipeline of future scientists.

Direct claims that the research could help to inform policy, be useful for industry, or lead to some solution to a real-world problem. General statements of improved understanding of a natural or technical process (i.e. climate change or ecosystems) were not included

Dissemination of research results for non-academic audiences in any form (web site, seminars, meetings, newspapers, magazines, etc.). Does not include $\mathrm{K}-12$ outreach

Includes partnerships with industry, non-profits, community groups, government bodies (local, state, national or international) and national laboratories

Note: These are the criteria, based on NSF's July 2007 broader impacts guidance document, that were used to code proposed broader impacts project summaries of research awards. Many projects had multiple broader impacts.

for neglecting to discuss broader impacts by $2005 .^{7}$ However, Holbrook argues that quantity alone does not equal success:

even if $100 \%$ of proposers and reviewers were to address [BIC] in their proposals and reviews, if they do so in a manner that lacks substance, the question as to the broader impacts of the proposal will remain unanswered. $(2005,445)$

Indeed, it appears that NSF will not send back a proposal if the researcher makes any attempt to address broader impacts, even if it is incorrect. For example, in a sample of 294 project summaries that consciously used a variation of the phrase "broader impact", nine of them (3\%) stated the potential impact on advancement of fundamental understanding as a broader impact, which should be considered under the intellectual merit criterion.

Although researchers are not required to use the words "broader impacts" in project summaries, it was interesting to find a large variation in the fraction of researchers who used the term among directorates: BIO, 21\%; CSE, 26\%; ENG, 40\%; GEO, 50\%; MPS, $10 \%$; OPP, 32\%; SBE, 22\%. This suggests that some directorates might place greater significance on BIC than others. In order to enrich my sample for researchers who had paid the most attention broader impacts, and were thus more likely to recognize the 
multiple choices of broader impacts activities for both science and society, I selected project summaries from this population. Thus, my sample does not represent the whole population of NSF awardees, but those who paid most attention to BIC.

Of the 294 project summaries, 89\% proposed broader impacts for science and 66\% proposed broader impacts for society. Thirty-one per cent proposed only broader impacts only for science, $7.5 \%$ proposed broader impacts only for society, and 59\% proposed broader impacts both for science and society (Figure 1). Many researchers proposed multiple broader impacts, and a small number of researchers misunderstood BIC. Those who misunderstood generally discussed the potential impacts on the advancement of scientific understanding, which should be reviewed as a part of the intellectual merit criterion.

A breakdown of the various broader impacts for science is detailed in Table 2. The vast majority of proposed broader impacts for science were related to training students - either mentoring or teaching classes. The one outlier was the Directorate of Social, Behavioral, and Economic Sciences, in which fewer than one-half of proposals mention training.

\section{Broader Impacts for Society}

Broader impacts for society included outreach and dissemination activities, partnerships with non-academic groups, or discussion of potential societal benefits. When coding potential societal benefits, I included only those that discussed how the research could help to address a societal problem or industrial or policy need. Descriptions of how results could improve understanding of a natural process, such as climate change, that did not directly state how the results could be useful to fix a problem or inform

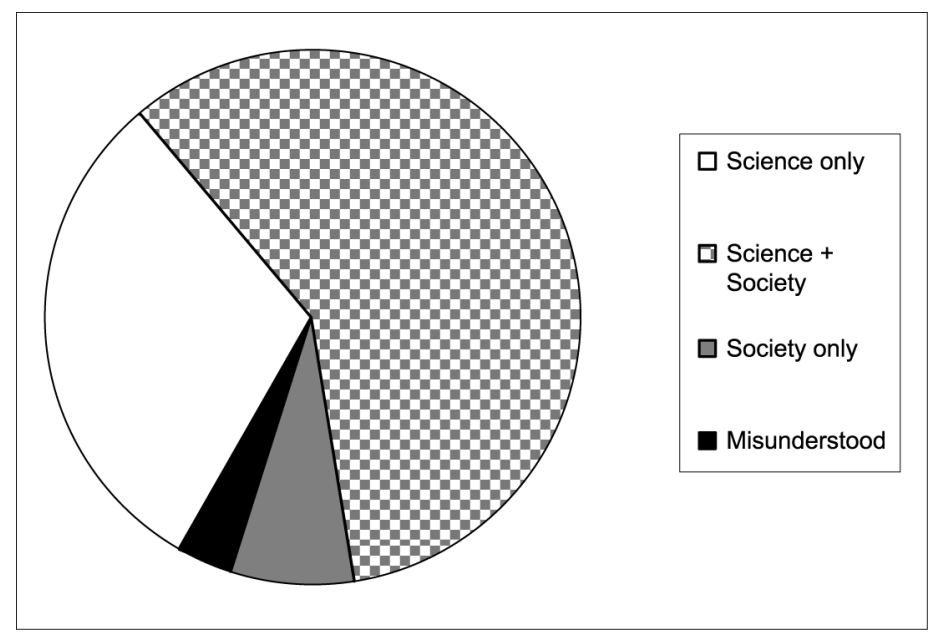

Figure 1 Proposed Broader Impacts for Science versus Society.

Note: Proposed broader impacts in a sample of 294 award project summaries that mentioned the term "broader impact" were coded by the criteria listed in Table 1. Many project summaries proposed more than one broader impact, and 3\% of proposals misunderstood the broader impacts criterion. The majority of proposals (59\%) propose impacts for both science and for society. 
Table 2 Frequency (\%) of Broader Impacts for Science, by Directorate

\begin{tabular}{lcccccccc}
\hline & BIO & CSE & ENG & GEO & MPS & OPP & SBE & All fields \\
\hline Training & $93^{*}$ & 62 & 83 & 90 & 83 & 88 & $40^{*}$ & 77 \\
K-12 students or teachers & 14 & 10 & $40^{*}$ & 19 & 17 & 33 & 7 & 20 \\
Broadening participation & 21 & 24 & $50^{*}$ & 26 & 29 & 26 & 21 & 28 \\
Interdisciplinary research & 31 & 36 & 26 & 14 & 24 & 12 & 14 & 22 \\
Collaborations with other universities & 12 & 12 & 17 & 33 & 26 & 40 & 33 & 25 \\
Infrastructure for science or university & 29 & 24 & 26 & 29 & 36 & 40 & 43 & 32 \\
\hline
\end{tabular}

Note: Based on the criteria in Table 1, the proposed broader impacts for science were coded in 42 project summaries from award proposals in each of six directorates and one office $(n=294)$. Of these, $89 \%$ proposed at least one broader impact for science. The distribution of proposed impacts varies somewhat by directorate. ${ }^{\star}$ Significant at a confidence interval of $90 \%$, by a two-tailed $Z$-test.

policy, were not counted as potential societal benefits. Using these criteria, $43 \%$ of broader impacts statements mention potential societal benefits. Remarkably, this result is very similar to a 1986 NSF survey, prior to introduction of BIC, which found that $53 \%$ of NSF-funded researchers believed that their work had practical implications beyond the advancement of knowledge (NSF 1988). This suggests that the 1997 BIC did not influence researchers to discuss potential uses more than the previous merit review criteria, which included the following as one of four review criteria:

utility or relevance of the research-the likelihood that the research can contribute to the achievement of a goal that is extrinsic or in addition to that of the research itself, and thereby serves as the basis for new or improved technology or assist in the solution of societal problems. (National Science Board and NSF Staff 1997)

Not unexpectedly, the fraction of researchers who mentioned potential societal benefit varied substantially across disciplines (Figure 2, white bars). For example, the fields that were identified as "use-inspired" by Stokes (1997)—such as engineering and economic sciences_-mentioned potential uses most frequently, approximately $70 \%$ of the time. Unexpectedly, however, fewer than one in five broader impacts statements in biology, the field that Stokes suggested to be the most "use-inspired", mention potential societal use. Discussion of potential societal use was similarly low in the Office of Polar Programs, an interdisciplinary research area that has societal implications for climate change policy.

The fraction of researchers who proposed broad dissemination activities also varied by field, albeit in a different pattern from societal benefits. Overall, 37\% of researchers proposed broad dissemination of results_-either by partnering with potential users during the course of researchers or by communicating results beyond the academic community (Figure 2, grey bars). However, the "use-inspired" fields of biological sciences and polar programmes were more likely than average to propose dissemination activities than other fields, at a frequency of $52 \%$ and $55 \%$, respectively.

I hypothesized that the researchers who discussed potential societal uses would be more likely to be "use-inspired" by a societal problem, and thus more likely to propose 


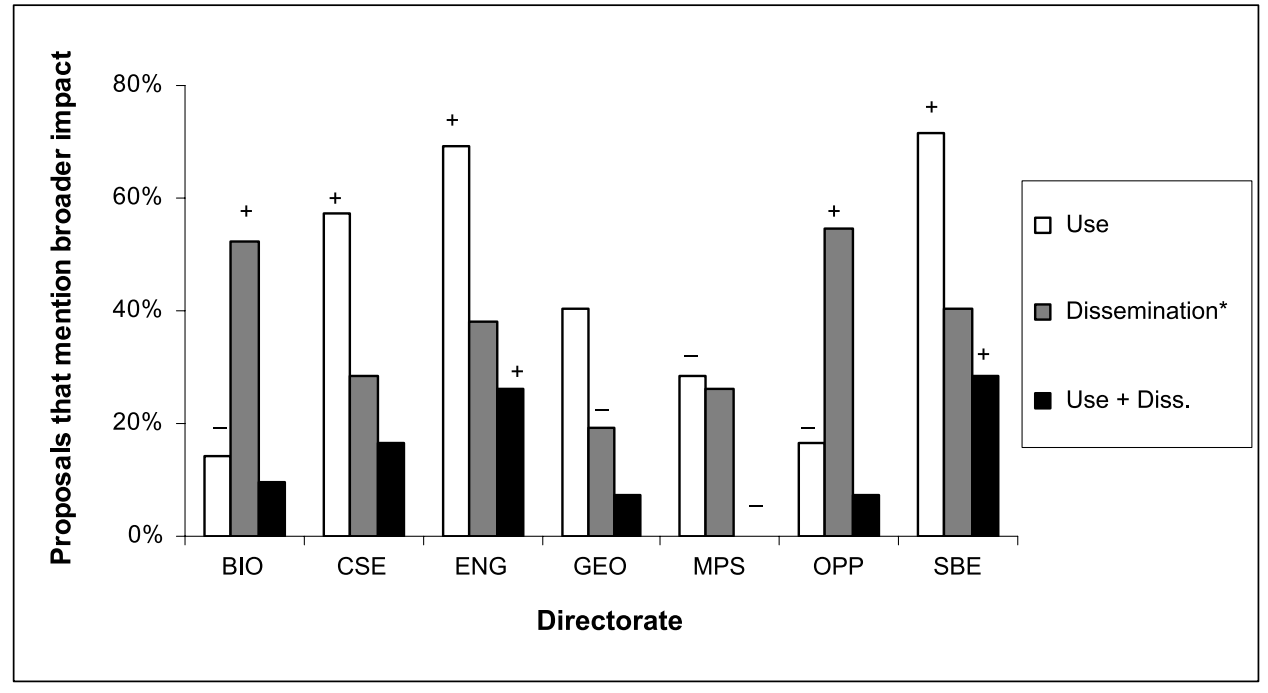

Figure 2 Proposed Broader Impacts for Society Vary among Research Fields.

Note: Based on the criteria in the lower part of Table 1, the proposed broader impacts for society were coded in 42 project summaries from award proposals in each of six directorates and one office $(n=294)$. Of these, $43 \%$ discussed potential societal benefits (white bars) and 37\% proposed dissemination activities (grey bars). Only $14 \%$ proposed both (black bars). The distribution of proposed impacts varies somewhat by directorate. * "Dissemination" includes both outreach and partnerships. Bars marked + or - are significant at a confidence interval of $90 \%$, by a two-tailed $Z$-test.

collaboration with or dissemination of results to potential users in society. However, the results of this analysis do not support the hypothesis. First, only $14 \%$ of all researchers both discussed potential societal benefits and broad dissemination activities, although this also varied by directorate (Figure 2, black bars). Researchers in the "useinspired" fields of engineering and social, behavioural, and economic sciences were more likely than those in other fields fall into this category. However, those who discussed potential societal benefit were no more likely than other researchers to propose dissemination activities (Figure 3).

To determine whether proposals that discussed broader impacts for society and proposed dissemination activities were the most "use-inspired", I compared the abstracts of those that discussed both societal benefit and dissemination with those that solely discussed potential benefits (data not shown). Of course, it is difficult to predict whether results will ultimately be useful for society, but I judged that about one-half of the proposals that addressed both potential societal benefits and dissemination activities had clear short-term applications with identified users that could be addressed mostly by that one study. Short-term applications included developing tools to improve traffic flow, providing conservation information for a particular species, or developing a new material with industry (for more examples see Table 3 ). In a similarly sized sample of proposals that only discussed potential benefits, less than one-third had clear short-term applications (data not shown). 


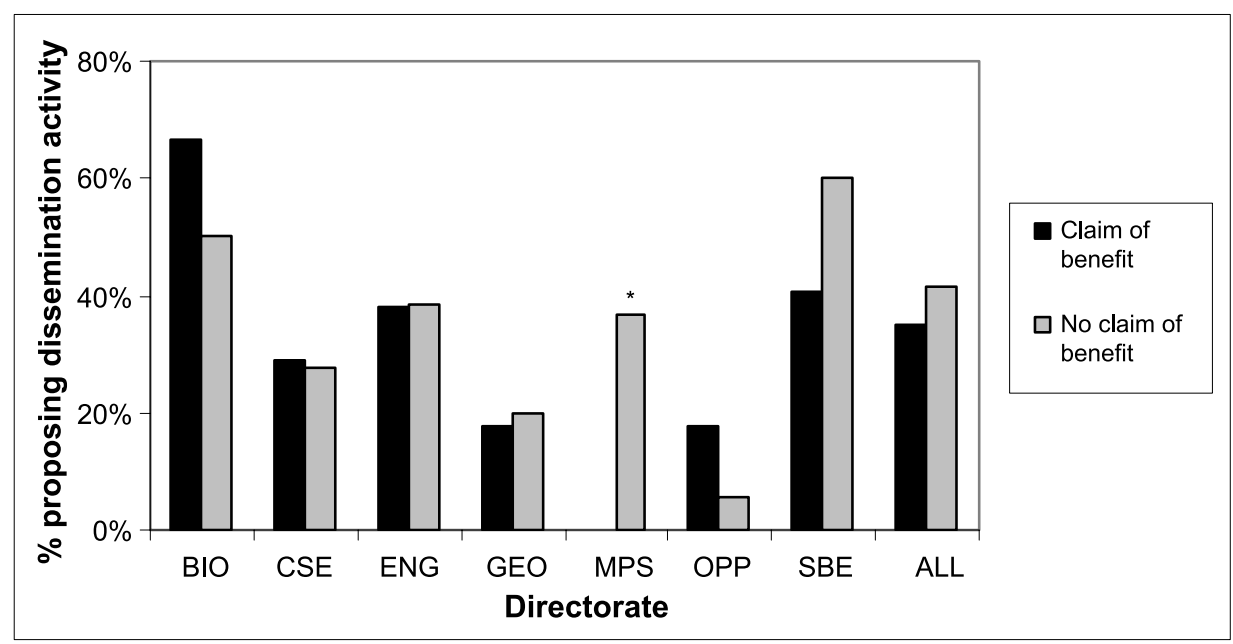

Figure 3 Claim of Societal Benefit does not Affect Likelihood of Dissemination.

Note: Based on the criteria in the lower part of Table 1, the proposed broader impacts for society were coded in 42 project summaries from award proposals in each of six directorates and one office $(n=294)$. Of these, $43 \%$ described potential societal benefits and $37 \%$ proposed dissemination activities. There was no statistical difference in the frequency of dissemination activities between proposals that discussed potential societal benefits (black bars) and those that did not (grey bars), except in MPS, where none of those who proposed dissemination activities also mentioned societal benefit.

\section{Discussion}

This study is the first to describe how NSF-funded researchers address the broader impacts merit review criterion. Among the researchers that deliberately use the term "broader impacts", $89 \%$ proposed broader impacts for science, $66 \%$ proposed broader

Table 3 Examples of "Use-inspired" Research at NSF

\begin{tabular}{|c|c|c|c|}
\hline Directorate & Title & Societal benefit & Dissemination activity \\
\hline SBE & $\begin{array}{l}\text { Food Insecurity in } \\
\text { Recently Resettled } \\
\text { African Refugee } \\
\text { Communities }\end{array}$ & $\begin{array}{l}\text { Identify who is most at risk } \\
\text { of food insecurity but why, } \\
\text { and in doing so would offer } \\
\text { useful programmatic } \\
\text { insights }\end{array}$ & $\begin{array}{l}\text { Refugees hired as interviewers. } \\
\text { Results distributed to } \\
\text { professional groups that } \\
\text { represent refugees and to } \\
\text { resettlement agencies }\end{array}$ \\
\hline ENG & $\begin{array}{l}\text { A Comprehensive } \\
\text { Framework for the } \\
\text { Efficiency Measurement } \\
\text { of Road Maintenance }\end{array}$ & $\begin{array}{l}\text { Both immediate and long- } \\
\text { term impacts on the } \\
\text { preservation of } \\
\text { infrastructure }\end{array}$ & $\begin{array}{l}\text { Broadly disseminate research } \\
\text { findings through a web site }\end{array}$ \\
\hline CSE & $\begin{array}{l}\text { From Actors To Actions: } \\
\text { Analysis And Alignment } \\
\text { Of Images, Video And } \\
\text { Text }\end{array}$ & $\begin{array}{l}\text { Improvements in video } \\
\text { retrieval from digital } \\
\text { libraries and video } \\
\text { surveillance }\end{array}$ & $\begin{array}{l}\text { Website with results, open } \\
\text { source code }\end{array}$ \\
\hline
\end{tabular}

Note: Fourteen per cent of the broader impacts statements included discussed both potential societal benefits and dissemination activities, and one-half of these had relatively clear potential short-term societal benefits. The above examples are demonstrative of such "use-inspired" projects. 
impacts for society, and 59\% proposed broader impacts both for science and society. However, the types of broader impacts that researchers chose to address varied widely across research areas. Of those who proposed broader impacts for society, $43 \%$ discussed potential societal benefits and 37\% proposed dissemination activities. However, researchers who recognized potential societal benefits were, overall, no more likely to propose broad dissemination activities than those who did not mention potential societal benefits. It appears that researchers who identified short-term societal benefits and specific users were somewhat more likely to disseminate findings than researchers who discussed more generalized societal benefits. These findings have a number of implications, discussed below, for the utility of "use-inspired" research as an alternative to the linear model of science and for policies to promote societal benefit from NSF-funded research.

\section{Are Researchers who Mention Potential Societal Benefit Really "Use-inspired"?}

As predicted anticipated by Stokes (1997), the fraction of researchers who mentioned potential societal use varied substantially across disciplines. For example, use-inspired fields like engineering and economic sciences mentioned potential societal benefits most frequently, approximately $70 \%$ of the time. Surprisingly, however, fewer researchers mentioned potential benefits in the "use-inspired" fields of biological sciences and polar programmes. This may reflect political calculations of researchers rather than actual differences in considerations of use. For example, biologists may be reluctant to mention potential health benefits for fear that their proposals will sound like they would be a better fit for programmes at the National Institutes of Health, which has a budget nearly four times larger than NSF. Similarly, researchers in polar programmes may believe it is safer to promote their work as basic research rather than mention the politicized topic of climate change policy, even if the research is use-inspired. Conversely, discussions of potential societal benefits may be overplayed in other fields if researchers believe that justification of research by potential societal benefit will increase the odds of funding, even if the work is truly inspired by a quest for fundamental understanding.

Biologists and polar scientists were least likely to mention potential social benefit, but were most likely to propose broad dissemination activities. The prevalence of efforts in these fields to disseminate results or to collaborate with users suggests that many researchers believe that their work has potential relevance, even if they did not mention the particular uses. This further supports the possibility that these fields suppress discussions of use even when the research is use-inspired, perhaps due to a perception that discussion of potential societal use could hurt the odds of receiving funding. Alternatively, scientists in these fields may propose dissemination activities to advance fundamental knowledge. For example, partnering with potential users such as industry or national laboratories may give access to critical equipment, whereas outreach to the public and policy-makers may gain support for basic research. However, if this were the case, one might expect physical sciences and geosciences, which depend on expensive scientific equipment as much or more than other fields, to show similarly high frequency of dissemination activities. Another observation that 
discredits the possibility that polar scientists engage in dissemination activities solely to advance fundamental knowledge is to compare their broader impacts to geoscientists, who have similar training and methodology, but are less focused on climate-related research. Geoscientists mentioned societal benefits more than twice as often as their counterparts in polar programmes, yet researchers in polar programmes were three times more likely to propose dissemination activities, suggesting that polar scientists were reluctant to mention the political subject of climate change in research proposals during 2007 and 2008. It will be interesting to see whether that trend shifts as the federal government dedicates more attention and resources to mitigating climate change.

In other fields, it appears that the potential societal benefits are probably overstated. For example, a majority of researchers in engineering, computer science, and social science discussed potential societal uses, but few proposed dissemination activities. In mathematics and physical sciences, about one-third discussed potential societal use, but none of these researchers also proposed dissemination activities. Thus, description of potential societal uses as broader impacts may sometimes represent curiosity-driven research that is use-justified for funding purposes, rather than use-inspired. Alternatively, researchers in these fields may have fewer incentives and rewards for dissemination activities than biology and polar programmes.

\section{Does "Use-inspired” Research Promote Greater Societal Benefit?}

In Pasteur's Quadrant, Donald Stokes (1997) argued that a "use-inspired" model of science, which considers both advances in fundamental knowledge and potential applications of research projects, would be more effective than the discredited linear model at connecting fundamental research with eventual applications:

The logic of classifying research on the basis of intended goals rather than known achievements rests on the fact that policy has to do with choice - the choices facing individual scientists, the choices facing those who match resources to alternative research uses at the retail or wholesale level. (Stokes 1997, 78)

BIC could potentially be used to classify research as Stokes suggests. However, it is very difficult to operationalize Stokes's model. First, as previously discussed, certain researchers may conceal potential applications for political and other reasons. In addition, reviewers cannot get inside the proposers' heads to distinguish research that was actually inspired by use from curiosity-driven research that was merely justified by use for the purposes of the grant proposal.

Even if it were possible to distinguish use-inspiration from use-justification, research suggests that it is unlikely use-inspiration alone would be sufficient to promote utilization of results by society. First, as Bozeman and Sarewitz (2005) argue, the potential societal benefits imagined by individual scientists might not necessarily be desired by the rest of society. In addition, one interesting study looked at variables that impact eventual utilization of research results, and found no correlation between researchers' focus on users' needs and the likelihood of knowledge utilization (Landry, Amara, and Lamari 2001). Two variables that correlate with increased utilization were 
dissemination of results and receptivity of users for the research. This suggests that asking a researcher to comment on the potential needs of users in BIC will not help to create more useful knowledge for society, unless it is accompanied by dissemination activities and the users need and trust the information that is provided. Indeed, a number of other scholars suggest that feedback activities between knowledge producers and users are critical for the utilization of scholarly research for innovation (Funtowicz 1993; Gibbons 1999; Sarewitz and Pielke 2007).

These findings, coupled with the results of this study, suggest that policies to promote the utilization of research results should focus on dissemination of results and on involvement of users in identifying potentially useful research proposals.

\section{Promoting the Utilization of Research Results: Policy Recommendations}

Since NSF does not track broader impacts outcomes, it is not known what broader impacts researchers actually carry out. However, the fraction of those who propose dissemination activities in this study (37\%) is similar to the fraction of researchers who reported having engaged in dissemination activities with non-academic users (27\%) in a survey of more than 1500 researchers across six fields (Landry, Amara, and Ouimet 2007). My finding that researchers who recognize potential societal benefits are no more likely to communicate with potential users suggests that knowledge flow between knowledge producers and users is not optimal. Further, my results suggest that including potential societal benefits in BIC is of limited use for optimizing knowledge flow, and ultimately societal benefit. Missed opportunities for dissemination of useful knowledge are likely due to reasons both external and internal to NSF, which must both be addressed in policies aimed at improving broader impacts outcomes. External reasons certainly include the academic culture that values pursuit of "pure knowledge" and rewards publication in academic journals, but does not often reward efforts like dissemination of results to non-academic audiences. Internal reasons may include a merit review process that does not give much weight to broader impacts and the lack of a system to hold awardees accountable for impacts outcomes.

One of the easiest policy changes that could lead to improved broader impacts would be to create a publicly available broader impacts outcomes reporting system. Such a system would help NSF to document more of its investment outcomes, hold researchers accountable for broader impacts proposals, and build a resource for other researchers as they plan their own broader impacts activities. This policy change may be forthcoming, since The America Competes Act of 2007 requires NSF to make final project reports available to the public. ${ }^{8}$

NSF could also implement changes in merit review that would increase the likelihood that useful information is both produced and communicated to potential users in a meaningful format. However, top-down strategies of funding agencies can only accomplish so much. Institutional innovation in universities will also be required to better match the supply, demand, and utilization of academic research for societal benefit. ${ }^{9}$ Below, I discuss some possible adaptations in the merit review process and the 
institutional structure of universities that could enhance the utilization of academic research by society.

\section{Modifying the Merit Review Process}

A study by Landry, Amara and Lamari (2001) found that one of the most important predictors of the utilization of research results was the receptivity of users to the information. Other researchers have shown that users are most receptive to information when users believe it to be credible, legitimate, and salient (Cash 2001; Cash et al. 2003; Guston 2001; McNie 2007).

To make connections between knowledge producers and potential users, NSF could invite representatives from user groups to help judge the potential societal utility of proposed research projects. The question of which users to invite to the table is difficult. Science policy scholars have recommended public participation in merit review (Bozeman and Sarewitz 2005; Guston 2004). Alternatively, Frodeman and Holbrook (2007) suggested inviting both experts in education and public outreach and researchers on science, technology, and society to participate on the merit review panel to judge the broader impacts. Both suggestions have merit, but would probably face problems in practice. First, one education and public outreach expert would not be qualified to review the large variety of broader impacts that may be proposed and would also be in competition with the rest of the panel, who are experts on the intellectual merit. Similarly, members of the general public would generally not be better qualified to judge the potential of a given research project to contribute to a particular societal outcome than the experts on the panel, as informed by their own life experiences.

I suggest that government mission agencies, which are charged with both applied research and development projects, may be more appropriate representatives of user needs. For example, the Department of Defense may be interested in certain engineering or computer science programmes; the Federal Reserve or Census Bureau might be involved in mathematics, statistics, or economics programmes; and the Environmental Protection Agency and the Bureau of Land Management in ecology programmes. Representatives from industry or non-profit groups might also participate as users with appropriate intellectual property protection. In some cases, representatives from user groups might identify potential uses even in curiosity-driven research or potential uses beyond those that the researchers identify in broader impacts statements. In other cases, mission agencies could help to define needs through special joint solicitations with NSF.

NSF already employs this strategy of joint solicitations on a limited basis. For example, the US Forest Service participates in the review process for proposals to the solicitation on "Dynamics of Coupled Human Natural Systems", the Department of Defense participates in a solicitation on the "Social and Behavioral Dimensions of National Security, Conflict and Cooperation", and the National Oceanic and Atmospheric Administration collaborates on a solicitation on "Communicating Hurricane Information". Additional opportunities could be created under a memorandum of under- 
standing between NSF and the US Agency for International Development ${ }^{10}$ on topics such as climate change adaptation.

\section{Promoting Broad Dissemination to Potential Users}

The Obama administration urged broad dissemination activities in a 4 August 2009 memo outlining priorities for science funding agencies:

Agencies should empower their scientists to have ongoing contact with people who know what's involved in making and using things, from the cost and competitive factors to the many practical constraints and opportunities that can arise when turning ideas into reality. (Orzag and Holdren 2009)

NSF could take advantage of this political push for broad dissemination by expanding its call for broad dissemination activities in BIC and at NSF Science and Technology Centers, which are required to undertake "activities that will facilitate knowledge transfer ... with the objective of disseminating and utilizing knowledge broadly in multiple sectors".

Of course, all modes of dissemination are not equal. Research by other groups has shown that, in the case of research to inform policy decisions, users are most receptive to information when it is seen as credible, as legitimate, and is salient. Credibility is generally established through peer review. Legitimacy-being perceived to be delivered without a political agenda-is improved through personal relationships between the knowledge producer and user. Salience is the most difficult criterion to meet, since it requires adaptation of information for the particular context and a timely delivery (Cash 2001; Cash and Buzier 2005; Cash et al. 2002 , 2003; Guston 2001; McNie 2007).

NSF should not require all researchers to engage in dissemination activities. First, designing an engagement process that creates credible, legitimate, and salient outputs requires both skill and time. Since broad dissemination activities take time and skill, NSF should offer supplementary awards to provide both funding and recognition to researchers who do have an interest in pursuing high-quality dissemination activities. Successful supplemental awards for dissemination activities should demonstrate support from potential users and should be reviewed by qualified experts to ensure that the dissemination activities are informed by prior research. When possible, researchers should also collaborate or consult with education and public outreach experts during execution of the project. Finally, supplemental awards for broader impacts should require publication of results in order to build a body of knowledge in "broader impacts" that could help to improve the quality of broader impacts activities and give both NSF and researchers credit for funding and performing broader impacts activities. Such a supplementary award mechanism could also be used to improve other broader impacts activities, such as K-12 outreach, teaching, and mentoring.

\section{A Role for Boundary Organizations}

Instead of placing the burden on the individual investigator to develop his or her own broader impacts proposal, it may be more effective to create capacity for broad 
dissemination activities at a campus level (see Burggren in this issue). One of the most effective mechanisms for connecting knowledge producers and users is the boundary organization, which acts as an intermediary between knowledge users and producers (Cash et al. 2003; Gieryn 1983; Guston 2001; McNie 2007). Unlike most university outreach offices and technology transfer offices, which communicate research results outward to unidentified users, a boundary organization for broad dissemination activities would promote the two-way flow of knowledge between the university and potential users - who may range from local businesses, non-profit organizations, or governments to international groups. They could match existing research projects with identified needs, suggest new areas of research to meet identified needs, and, for interested researchers, facilitate interactions between knowledge producers and users that will inform both the design and communication of use-inspired research to enhance its utility.

Boundary organizations are relatively rare on American campuses. Why? Perhaps due to the historical separation between basic science, applied science, and development, connections between the two have been largely overlooked by participants across the spectrum. The best examples of university boundary organizations were established by Congressional directives: the Smith-Lever Act of 1914 and the Sea Grant Act of 1966 authorized extension offices to help promote connections between university research and advances agricultural methods and oceans management, respectively (Cash 2001; Cash and Moser 2000). In today's highly technical society, which faces unprecedented challenges such as energy independence and climate change, perhaps it is time for Congress to authorize new extension functions at universities to address these new societal challenges. Also, states might consider funding an extension office at a state university to address state needs.

The government could spur development of new boundary organizations, but successful boundary-spanning efforts will also require organizational innovation in universities that will create incentives for interdisciplinary research, for collaborations with partners in other sectors, and for dissemination and outreach activities (Bartel, Krasny, and Harrison 2003). Further, to create credible, legitimate, and salient information, boundary organizations should recruit people who understand technical content, societal needs, the cultures of researchers and users, and communication and management techniques for bridging these different worlds. Training people with expertise in all of these areas may necessitate new education models, which combine technical skills with practical experience in the sectors where that technical information might be utilized (Hill 2007). New graduate programs such as the Professional Science Masters may help to fill the growing need for this type of training.

\section{Conclusion}

Past research demonstrates that broad dissemination of research results in a meaningful format for potential increases the likelihood of utilization for societal benefit. However, this study demonstrates that only a small fraction of researchers who call 
attention to potential societal benefits also propose to disseminate their results to potential users. Thus, inclusion of potential societal benefit as a broader impact probably does not increase the likelihood of realizing societal benefits. To increase the likelihood of societal benefit from academic research, a combination of policies should be considered, including a system for reporting broader impacts and collaborating with users to help identify the potential utility of research proposals. In addition, highquality dissemination activities should be supported by NSF and the results of these efforts should be published in order to build a body of knowledge on dissemination techniques. New boundary organizations between universities and users could be helpful for facilitating dissemination efforts.

\section{Acknowledgements}

The author is grateful to Roger Pielke, Jr, and Edward Hackett for insightful comments on earlier versions of this manuscript, and to NSF historian Mark Rothberg for discussing the history of NSF's merit review criteria.

\section{Notes}

[1] Available from http://mynew.asu.edu/use-inspired-research; INTERNET.

[2] The National Science Board is NSF's independent oversight board. The President nominates and the Senate and confirms Board members to six-year terms.

[3] Private communication with Mark Rothberg, NSF historian.

[4] Available from www.nsf.gov/pubs/gpg/broaderimpacts.pdf; INTERNET.

[5] Available from www.nsf.gov/pubs/gpg/broaderimpacts.pdf; INTERNET.

[6] Available from http://www.dimensionresearch.com/resources/calculators/ztest.html; INTERNET.

[7] According to Dr Kathy Olsen, Deputy Director of NSF, 325 proposals were returned without review (out of 28,676 proposals) in 2005. Advisory Committee for Geosciences, 4-6 October 2006.

[8] Section 7010: Reporting of Research Results. Public Law 110-69, signed 9 August 2007.

[9] The Center for the Study of Interdisciplinarity has a collection of links to both topdown and bottom-up approaches to BIC. Available from http://www.csid.unt.edu/topics/ bestpractices.html; INTERNET.

[10] April 2008. Full text available from http://www.nsf.gov/attachments/111504/public/USAIDNSF-MOU-signed-version.doc; INTERNET.

\section{References}

Bartel, A. S., M. Krasny, and E. Z. Harrison. 2003. Beyond the binary: Approaches to integrating university outreach with research and teaching. Journal of Higher Education Outreach and Engagement 8 (2): 89.

Bozeman, B., and D. Sarewitz. 2005. Public values and public failure in US science policy. Science and Public Policy 32 (2): 119-36.

Branscomb, L., G. Holton, and G. Sonnert. 2002. Science for society. In AAAS science policy yearbook, edited by A. H. Teich, S. D. Nelson and S. J. Lita, pp. 397-433. Washington, DC: AAAS.

Brint, S. 2005. Creating the future: New directions' in American research universities. Minerva 43 (1): 23-50. 
Bush, V. 1945. Science: The endless frontier: A report to the President. Office of Scientific Research and Development. Washington, DC: US Government Printing Office. Available from http:// nsf.gov/lpa/nsf50/vbush1945.htm; INTERNET.

Cash, D. W. 2001. In order to aid in diffusing useful and practical information: Agricultural extension and boundary organizations. Science Technology \& Human Values 26 (4): 431-53.

Cash, D., F. Alcock, B. Clark, N. Dickson, J. Jäger, and R. Mitchell. 2002. The institutional challenges of producing salient, credible, and legitimate regional integrated assessments. Paper presented at the International Workshop on Regional Integrated Assessment of Climate Impacts, Harvard, USA, 16-20 September.

Cash, D., and J. Buzier. 2005. Knowledge-action systems for seasonal to inter-annual climate forecasting: Summary of a workshop. A report to the roundtable on science and technology for sustainability. Washington, DC: National Research Council.

Cash, D. W., W. C. Clark, F. Alcock, N. M. Dickson, N. Eckley, D. H. Guston, J. Jäger, and R. B. Mitchell. 2003. Knowledge systems for sustainable development. Proceedings of the National Academy of Sciences 100 (14): 8086-91.

Cash, D. W., and S. C. Moser. 2000. Linking global and local scales: Designing dynamic assessment and management processes. Global Environmental Change 10 (2): 109-20.

Clark, W. 2007. Sustainability science: A room of its own. Proceedings of the National Academy of Sciences 104 (6): 1737-8.

Dilling, L. 2007. Towards science in support of decision making: Characterizing the supply of carbon cycle science. Environmental Science and Policy 10: 48-61.

Etzkowitz, H., and L. Leydesdorff. 2000. The dynamics of innovation: From national systems and "mode 2" to a triple helix of university-industry-government relations. Research Policy 29 (2): $109-23$.

Frodeman, R., and J. B. Holbrook. 2007. Science's social effects. Issues in Science and Technology (Spring): 28-30.

Funtowicz, S. O. 1993. Science for the post-normal age. Futures 25 (7): 739-55.

Gibbons, M. 1999. Science's new social contract with society. Nature 402 (6761 Suppl.): C81-4.

Gibbons, M., C. Limoges, H. Nowotny, S. Schwartzman, P. Scott, and M. Trow. 1994. The new production of knowledge, the dynamics of science and research in contemporary societies. London: Sage Publishing, Ltd.

Gieryn, T. F. 1983. Boundary-work and the demarcation of science from non-science: Strains and interests in professional ideologies of scientists. American Sociological Review 48 (6): 781-95.

Goldston, D. 2009. Budget instructions. Nature 460 (25). Available from http://www.nature.com/ news/2009/090902/full/461025a.html; INTERNET.

Green, R. J., and W. Lepkowski. 2006. A forgotten model for purposeful science. Issues in Science and Technology 22 (2): 69.

Guston, D. H. 2001. Boundary organizations in environmental policy and science: An introduction. Science, Technology, and Human Values 26 (4): 399-408.

Guston, D. H. 2004. Forget politicizing science. Let's democratize science. Issues in Science and Technology 21 (1): 1-4.

Guston, D. H., and K. Keniston. 1994. The fragile contract: University science and the federal government. Cambridge, MA: MIT Press.

Hill, C. T. 2007. The post-scientific society. Issues in Science and Technology 24 (1): 78-84.

Holbrook, J. B. 2005. Assessing the science-society relation: The case of the US National Science Foundation's second merit review criterion. Technology in Society 27 (4): 437-51.

Huberman, M. 1990. Linkage between researchers and practitioners: A qualitative study. American Educational Research Journal 27: 363-91.

Kevles, D. J. 1977. The National Science Foundation and the debate over postwar research policy, 1942-1945: A political interpretation of science-the endless frontier. Isis 68 (1): 5-26.

Kitcher, P. 2001. Science, truth, and democracy. New York: Oxford University Press. 
Kleinman, D. L. 1995. Politics on the endless frontier: Postwar research policy in the United States. Durham, NC: Duke University Press.

Landry, R., N. Amara, and M. Lamari. 2001. Climbing the ladder of research utilization: Evidence from social science research. Science Communication 22: 396-422.

Landry, R., N. Amara, and M. Ouimet. 2007. Determinants of knowledge transfer: Evidence from Canadian university researchers in natural sciences and engineering. The Journal of Technology Transfer 32 (6): 561-92.

Marburger, III, J. H., and M. E. Daniels, Jr. 2003. FY 2005 interagency research and development priorities, June 5 , memorandum.

Marinova, D., and J. Phillimore. 2003. Models of innovation. In The international handbook on innovation, edited by L. V. Shavinina, pp. 44-53. Oxford: Elsevier.

Mazuzan, G. 1994. The National Science Foundation: A brief history. Publication NSF 8816. Washington, DC: National Science Foundation.

McNie, E. C. 2007. Reconciling the supply of scientific information with user demands: An analysis of the problem and review of the literature. Environmental Science and Policy 10 (1): 17-38.

National Academy of Public Administration. 2001. A study of the National Science Foundation's criteria for project selection.

National Academy of Sciences. 2006. Rising above the gathering storm: Energizing and employing America for a brighter economic future. Washington, DC: The National Academies Press.

National Science Board. 1967. Seventeenth annual report of the National Science Foundation. Available from http://www.nsf.gov/pubs/1967/annualreports/ar_1967_appendix_f.pdf; INTERNET.

National Science Board and National Science Foundation Staff. 1997. Task force on merit review. March. Available from http://www.nsf.gov/pubs/1997/nsbmr975/nsbmr975.htm; INTERNET.

National Science Foundation. 1988. Proposal review at NSF: Perceptions of principal investigators. Washington DC: National Science Foundation.

Orzag, P. R., and J. P. Holdren. 2009. Memorandum for the heads of executive departments and agencies. Office of Management and Budget and Office of Science and Technology Policy, The White House, 4 August.

Pielke, R., and R. Byerly. 1998. Beyond basic and applied. Physics Today 51 (2): 42-6.

Sarewitz, D. R. 1996. Frontiers of Illusion: Science, technology, and the politics of progress. Philadelphia, PA: Temple University Press.

Sarewitz, D., and R. A. Pielke. 2007. The neglected heart of science policy: Reconciling supply of and demand for science. Environmental Science and Policy 10 (1): 5-16.

Smith, B. L. R. 1990. American science policy since World War II. Washington, DC: Brookings Institution Press.

Stokes, D. E. 1997. Pasteur's quadrant: Basic science and technological innovation. Washington, DC: Brookings Institution Press. 